\title{
RESEÑAS
}




\section{EL AULA Y LA \\ CONSTRUCCION \\ DEL SABER \\ MATEMATICO EN \\ EL NIÑO}

\section{Blanca Cecilia Carrasco Pinilla}

\section{INTRODUCCION}

El presente trabajo nació como fruto de la inquietud, compartida por muchos profesores de secundaria, sobre las dificultades y el bajo rendimiento de los alumnos en áreas tales como la matemática y el lenguaje, asignaturas que requieren para su comprensión altos niveles de abstracción y dominio del lenguaje.

Aunque las dificultades encontradas por los alumnos se deban a diversos factores, se quiso explorar específicamente lo relacionado con la apropiación del conocimiento matemático, el desarrollo del lenguaje y el desarrollo del razonamiento abstracto.

La investigación se abordó desde un marco teórico basado en la teoría de Piaget con los siguientes objetivos:

1. Desarrollar una estrategia que permita al alumno aumentar su nivel de razonamiento abstracto.

2. Identificar datos relevantes para la comprensión de las relaciones entre razonamiento abstracto, aptitud verbal y rendimiento en matemática. 3. Aumentar el nivel de satisfacción del estudiante en el aprendizaje de la matemática.

4. Equiparar la matemática a los lenguajes ordinarios utilizados por el estudiante provocando niveles crecientes de dificultad.

5. Incrementar la competencia lingüística teniendo en cuenta sus dos funciones: el lenguaje como objeto de interpretación y el lenguaje como metódica con la cual se aproxima al fenómeno.

\section{BASES TEORICAS DEL ESTUDIO}

Según Piaget el conocimiento no se adquiere pasivamente; no es una respuesta condicionada que resulta de un determinado estímulo cuando las respuestas correctas se han reforzado adecuadamente. Es el resultado de la actividad del sujeto en relación con el ambiente que lo rodea. La interacción del ser humano con su ambiente por medio de la acción es lo que hace posible que la capacidad de razonar, de comprender y de conocer se desarrolle. El desarrollo mental se da por etapas que siguen un cierto orden y se coordinan unas con otras en niveles de mayor complejidad obedeciendo a los siguientes criterios (Inheler y Piaget, 1975):

1. Su orden de sucesión es constante. Se suceden en orden invariable aunque varíe la edad promedio para cada una de ellas de acuerdo con los factores individuales y sociales. 
2. Cada etapa se caracteriza por una estructura de conjunto que puede desempeñar una función explicativa respecto a las principales reacciones particulares.

3. Estas estructuras son integrativas y no sustitutivas. Cada una supone la anterior y la integra, preparando así la siguiente, a la cual se integra a su vez. Cada etapa subsiste en las siguientes como subestructura sobre la cual etapas posteriores desarrollan nuevas características.

Para que el desarrollo mental pueda darse se requiere el desarrollo orgánico y la maduración fisiológica normales, la actividad de la persona

en la interacción con el medio que lo rodea. El desarrollo mental se da por una construcción progresiva que constituye un proceso de equilibración, de autorregulación cognitiva por medio de la acción del sujeto como respuesta a su ambiente y a las preguntas que éste le plantea.

El desarrollo mental obedece al mecanismo de adaptación en sus dos aspectos: asimilación como incorporación de los objetos y experiencias a los esquemas de su actividad propia, y acomodación como reajuste de las estructuras en función de las transformaciones y desequilibrios sufridos.

Cuando el niño llega a ser capaz de desligar su pensamiento de lo concreto presente o de lo inmediatamente representado, comienza a darse el paso entre el pensamiento concreto y el pensamiento formal o "hipotético - deductivo".

Las operaciones lógicas pueden independizarse de lo concreto y pasar a efectuarse sobre ideas expresadas con palabras o con símbolos matemáticos, sin apoyarse en la percepción, la experiencia o las creencias del sujeto.

De ahí que al niño que no ha alcanzado este nivel se le presentan dificultades en problemas matemáticos que resuelve si puede manipular los objetos, o si puede razonar a partir de representaciones inmediatas. Operaciones conocidas se hacen más difíciles cuando han de realizarse en el plano del lenguaje y de los enunciados verbales. En este caso el razonamiento es más difícil porque está relacionado con simples hipótesis.

La constitución del pensamiento es el resultado de un proceso que se inaugura con la toma de conciencia y se consolida cuando se establece una asociación entre la representación de la cosa y la representación de la imagen verbal. Enlazar las palabras y las imágenes hace posible el pensar propiamente dicho. Con la adquisición de la palabra, se inicia un paso decisivo en el desarrollo de la capacidad para percibir la realidad. La coexistencia de lo simbólico, lo imaginario y lo real, rige no sólo la relación del hombre con su semejante, sino que está enclavada en la comunicación que el hombre expresa de su realidad.

Lograr la síntesis entre la identidad de percepción y la identidad de pensamiento es ascender al nivel del conocimiento, es llegar al pensamiento abstracto. Las definiciones abstractas, son la base para la formación de una nueva estructura de pensamiento: la discursividad que produce el objeto teórico del conocimiento.

El desarrollo de la estructura del lenguaje se construye en dos sentidos: el contextual, generado por el ámbito social en que se desarrolla el individuo y el formal, generado en la escuela. Si se tiene en cuenta que la matemática, al igual que cualquier otro discurso, es 
un lenguaje sobre la realidad, se comprende en qué forma el uso correcto de la estructura lógica constituye el fundamento de la construcción de las nociones matemáticas y en qué forma el uso de la matemática debe ser un lenguaje que facilite el manejo de las diferentes estructuras reales. El desarrollo de la competencia lingüística es garantía del aprendizaje y del conocimiento matemático. Importan por tanto, en el contexto educativo la constitución de un lenguaje común que dinamice el proceso de apropiación del conocimiento y que partiendo del lenguaje del niño permita que el maestro se vincule al espacio vital en que éste se desempeña.

El reto del pedagogo es conducir al alumno a la formación de conceptos y a que descubra por sí mismo las relaciones y propiedades matemáticas utilizando un método socializador, activo, dinámico y creativo que permita el desarrollo del pensamiento lógico reflexivo.

\section{HIPOTESIS}

La hipótesis propuesta es la siguiente:

El razonamiento abstracto se incrementa significativamente si se utiliza en forma adecuada la estructura gramatical, se garantiza la comprensión de enunciados literales en las alumnas y se trata la matemática como un lenguaje entre lenguajes.

\section{METODOLOGIA Y PROCEDIMIENTO}

Se seleccionó una muestra de 88 alumnas del grado sexto (primero de bachillerato) tomando 41 como grupo Experimental y47 como grupo Criterio, alumnas del colegio de la Presentación las Ferias, y con ellas se realizó la experiencia durante el año lectivo 1987, habiendo realizado el año anterior una observación libre que permitió realizar los ajustes y probar los instrumentos.

\section{INSTRUMENTOS}

1. Se realizaron entrevistas individuales de tipo clínico donde se aplicó la prueba de lógica operatoria con el fin de conocer el nivel de dominio de las estructuras y nociones elementales propias del pensamiento concreto.

2. Se aplicó una prueba inicial de conocimientos en las áreas de matemáticas y español y se revisaron las calificaciones de 50 . de primaria en estas dos áreas.

3. Para detectar la modificación del contexto educativo se aplicó una prueba final de conocimientos matemáticos y pruebas de aptitud académica en razonamiento abstracto, razonamiento numérico y comprensión lectora.

4. Para medir el efecto final en términos de rendimiento se revisaron las calificaciones finales correspondientes al grado sexto en las áreas de Matemáticas y Español.

\section{ANALISIS DE RESULTADOS Y CONCLUSIONES}

Los resultados obtenidos permiten constatar la existencia de diferencias significativas entre los grupos Experimental y Criterio en las áreas de Matemáticas y Español. Siendo mayor la diferencia encontrada en el área de matemáticas donde la modificación del contexto educativo fue más extensa y con mayor rigor. 
La incorporación de la Geometría como dibujo, permitió a las alumnas interiorizar con mayor facilidad y con más libertad las nociones geométricas básicas y contribuyendo a la creación de un clima de agrado hacia esta asignatura.

La aplicación de la prueba de aptitud académica en aspectos tales como razonamiento abstracto, comprensión lectora y razonamiento numérico permite comprobar que las diferencias encontradas son significativas y que se presentaron en el siguiente orden de mayor a menor: razonamiento abstracto, comprensión lectora y razonamiento numérico.

Se constata además el cambio de actitud hacia la matemática lo cual favorece la interiorización de los conocimientos.

La hipótesis general fue corroborada en gran parte: se acrecentó el nivel de razonamiento de los estudiantes, y como consecuencia hubo mayor rendimiento académico en las alumnas del grupo experimental; se incrementó la comprensión lectora y con ello la capacidad de analizar y de sintetizar.

Se concluye por tanto que existe una estrecha relación entre el nivel de razonamiento, la comprensión lectora y el rendimiento en matemáticas.

Para poder construir una teoría sobre el proceso de apropiación del conocimiento es necesario continuar la investigación para observar el efecto que la modificación del contexto educativo produce en la cohorte. 